\title{
Development of the Swiss Database for dosing medicinal products in pediatrics
}

\author{
Romy Tilen ${ }^{1,2,5}$ (1) $\cdot$ Dalibor Panis $^{1} \cdot$ Samuel Aeschbacher ${ }^{3} \cdot$ Thomas Sabine $^{4} \cdot$ Henriette E. Meyer zu Schwabedissen $^{5}$. \\ Christoph Berger ${ }^{1,2}$
}

Received: 17 August 2021 / Revised: 18 October 2021 / Accepted: 23 October 2021 / Published online: 5 November 2021

(c) The Author(s) 2021, corrected publication 2021

\begin{abstract}
In daily paediatrics, drugs are commonly used off-label, as they are not approved for children. Approval is lacking because the required clinical studies were limited to adults in the past. Without clinical studies, evidence-based recommendations for drug use in children are limited. Information on off-label drug dosing in children can be found in different handbooks, databases and scientific publications but the dosing recommendations can differ considerably. To improve safety and efficacy of drugs prescribed to children and to assist the prescribers, stakeholders in Swiss paediatrics started a pilot project, supported by the Federal Office of Public Health, with the aim to create a database, providing healthcare professionals with so called "harmonised" dosage recommendations based on the latest available scientific evidence and best clinical practice. A standardised process for dosage harmonisation between paediatric experts was defined, guided and documented in an electronic tool, developed for this purpose. As proof of principle, a total of 102 dosage recommendations for 30 different drugs have been nationally harmonised in the pilot phase considering the current scientific literature and the approval of the most experienced national experts in the field.

Conclusion: This approach paved the way for unified national dosage recommendations for children. Reaching the project's milestones fulfilled the prerequisites for funding and starting regular operation of SwissPedDose in 2018. Since then, the database was extended with recommendations for 100 additional drugs.

\section{What is Known:}

- Prescribing off-label is a common practice among paediatricians, as many drugs are still not authorised for use in children.

- Some countries developed national drug formularies providing off-label dosage recommendations.

What is New:

- Comparison of published dosage recommendations in known drug handbooks and online databases show substantial differences and heterogeneity, revealing the need for harmonisation.

- The design of a tool for standardised harmonisation of dosage recommendations, based on information collected on currently applied dosages, latest scientific evidence and the approval of experts.
\end{abstract}

Communicated by Peter de Winter

Romy Tilen

romy.tilen@swisspeddose.ch; romy.tilen@kispi.uzh.ch

Dalibor Panis

dalibor.panis@swisspeddose.ch

Samuel Aeschbacher

s.aeschbacher@infoserv-it.ch

Thomas Sabine

sabine.thomas@bag.admin.ch

Henriette E. Meyer zu Schwabedissen

h.meyerzuschwabedissen@unibas.ch

Christoph Berger

christoph.berger@kispi.uzh.ch
1 SwissPedDose, Zurich, Switzerland

2 Department of Infectious Diseases and Hospital Epidemiology, University Children's Hospital Zurich, Zurich, Switzerland

3 Infoserv, Evilard, Switzerland

4 Federal Office of Public Health, Bern, Switzerland

5 Biopharmacy, Department of Pharmaceutical Science, University Basel, Basel, Switzerland 
Keywords Children · Drug safety · Off-label use ·

Prescribing $\cdot$ Web-based software

\begin{tabular}{ll}
\multicolumn{2}{l}{ Abbreviations } \\
ADR & Adverse drug reaction \\
FOPH & Federal Office of Public Health \\
SmPC & Summary of Product Characteristics \\
SOP & Standard operating procedures \\
TPA & Therapeutic Products Act
\end{tabular}

\section{Introduction}

Children have often been excluded from the dosage-finding process and from drug approval [1]. Accordingly, most of the drugs administered in paediatrics are not authorised for use in children and as a result, there is no dosage recommendation for children on the drug label. Legal efforts worldwide aim at facilitating the development, performance of studies and accessibility of medicines in paediatrics. They target to ensure that more child-friendly medicines are approved and made available on the market [2-5]. Even if these regulations have stimulated paediatric research and the number of new products with specific paediatric indications is encouraging, there is still an immense lack of high-quality information about medicines used for children. A recent survey on paediatric information in the summary of product characteristics (SmPC) of medicines currently available in Germany concluded that the new regulation did not significantly stimulate clinical studies with medicines of which the patent has already expired [6]. Importantly, prescribing a medication for a specific age group or for a specific disorder not covered by the terms of its marketing authorisation and, therefore, not in accordance with the SmPC is called off-label use [7]. The proportion of offlabel use in children varies, depending on factors such as age, health care setting and quantity of prescribed drugs. A survey in a Swiss university hospital revealed a proportion of off-label and unlicensed use in the inpatient sector of about $50 \%$ [8]. The reported numbers are referring to the total number of prescriptions in the investigated sector which is comparable with reports on off-label/unlicensed use for hospitalised children in other countries [9-11] and has not improved since the paediatric regulation $[12,13]$. Without another choice, off-label use is a widespread and common practice for paediatrician [14, 15], without implying improper or illegal drug use [16]. Importantly, off-label use does not exclude that there is extensive clinical experience and also data for the intended use [17]. For some drugs, there is recent scientific data of high quality and ample experience for the dosage used in practice which may deviate from the information in the SmPC [18]. In addition, information in drug labels, such as warnings or contraindications for use in children and adolescents has in most cases only legal, but no medical meaning [6, 19]. On-label does not necessarily mean that it is based on current scientific evidence, as such a change in the SmPC has to be submitted by the marketing-authorisation holder [20]. Thus, off-label prescription is the paediatricians' everyday practice, while following the label may not always be appropriate in children.

In 2008, 1 year after the introduction of the paediatric regulation in Europe, the Swiss Confederation recognised the unsatisfactory situation within paediatric drug therapy in Switzerland [21]. In particular, serious adverse drug reactions (ADRs) occurred three times more often in children than in adults [22-24]. A considerable proportion of these ADRs were due to mistakes in prescription, including incorrect dosages. The prescription of drugs should be based on the best available evidence, including information gathered in peer-reviewed scientific studies. In paediatrics, this information is commonly gathered by experts in academia (university hospitals), but it often does not find its way into the SmPCs' marketing authorisation [25, 26].

The recognition of the Swiss federal government was in accordance with the call of Swiss paediatricians that the systematic collection and transparent provision of scientific data and clinical experience in paediatrics is of central importance [21]. This led to the decision of the federal government to extend the Therapeutic Products Act (TPA). This extension enabled the introduction of a national database for the collection, evaluation, harmonisation and publication of data relating to the prescription, supply and use of medicinal products in paediatrics [27].

Stakeholders in Swiss paediatrics launched the pilot project that we present here. Its overall aim was the development of this database to provide healthcare professionals with national harmonised dosage recommendations. Accordingly, the milestones of the project were the design of a web-based tool for the harmonisation of dosage recommendations for children in Switzerland, based on the information collected on currently applied dosages, latest scientific evidence from the literature, and the clinical experience and approval of experts and the publication of the results in a web application accessible to healthcare professionals free of costs in Switzerland and worldwide.

\section{Methods}

\section{Collection of drug consumption data}

The project started with a collection of drugs used in 8 contributing children's hospitals in Switzerland, in order to 
decide which drugs are the most commonly used and should be harmonised first.

Data on drug consumption were collected from the hospital pharmacies including the regular consumption of all patients and all departments within the hospitals over a year. The lists were summarised and limited to 40 drugs. This "Top 40 list" was the basis for the collection of in-house dosage recommendations for these drugs from the participating hospitals.

\section{Online platform to track the harmonisation process}

In order to define harmonised dosage recommendations for off-label drug use in Switzerland, a standardised harmonisation process was developed in which the dosage recommendations currently used for prescriptions in the hospitals were compiled, compared with the current scientific literature and the results assessed and approved among experts. In cooperation with the IT service provider Infoserv (Evilard, Switzerland), an online platform - The Harmonisation Tool - was designed to guide the process and to document discussions and decisions, so that all steps are traceable at any time.

The harmonisation tool as a test and productive version can be accessed online by the project participants. The data entered into the harmonisation tool are stored within a SQL database. The eventually harmonised data is automatically published in XML format and imported in a web application that can be accessed by health care professionals (Fig. 1). In a separate administration tool, the roles of the harmonisation participants and all codes (indications, routes of administration, units, ATC codes, remarks etc.) can be managed by the coordinating pharmacists (coordinator).

\section{Operational project team}

The team consists of data experts, harmonisation experts and a coordinator. The requirements for the experts were defined before the recruitment. They were delegated by their clinic directors, approved by the project manager and finally had to undergo training before they were able to participate in the harmonisation process. From each of the 8 hospitals, 1 hospital pharmacist (data expert) with access to the internal dosing guidelines joined the project team, as well as 3 senior paediatricians (harmonisation experts) with the most comprehensive professional experience in one of the following specialties: infectious diseases, neonatology and general paediatrics. Three expert groups of 8 harmonisation experts were formed and each group was led by a designated coordinator.

\section{Process of data collection}

In order to optimise the data collection, evaluation and consensus finding, a standardised process was developed for the data experts, the 3 harmonisation expert groups and the coordinators. The process for dosage harmonisation (Fig. 2) foresees that the coordinators request electronically the internal dosage recommendations and its underlying references from the 8 data experts. The request is limited to one drug-indication pair supplemented with the route of administration (e.g. paracetamol-fever-intravenous route) and the age and weight categories, if applicable. The data experts analyse the internal dosing guidelines and check with inhouse specialists where necessary. The data experts send the in-house dosage recommendation via the harmonisation tool to the coordinator. If at least 4 of 8 hospitals are using the drug for this indication and route of administration, the coordinator starts the harmonisation round and performs a literature review.

\section{Literature review}

A semi-structured literature review was conducted to find recent dosage recommendations in the literature and to compare the findings with the collected dosing guidelines from the participating hospitals.

The literature review started by analysing the "Therapeutic indications" and "Posology" sections of the drugs' newest SmPCs approved and published by the Swiss Agency for Therapeutic Products, the European Medicine Agency or the Food and Drug Administration, respectively [28-30]. For that the drug formulation matching the route of administration was selected. It was checked whether the drug is licensed for any age group within the paediatric population, and if so, the respective dosage recommendation was included. Then peer-reviewed literature sources were consulted. At first, well-known international and national referenced drug handbooks and online databases were searched for the drug and its dosages for each indication [31-44]. Additionally, we searched for the selected drug filtered by age (newborn, child), and if possible, the indication/route of administration of interest on websites of medical societies, in the PubMed database, and in the Cochrane Library for national and international consensus guidelines and systematic reviews. Original literature referenced in these literature sources was analysed, and paediatric drug dosage information contained therein was taken into account.

The information found is gathered in a PDF summary containing all published dosage recommendations, the related references, and if applicable, the corresponding age and weight categories for which the recommendations are made. 


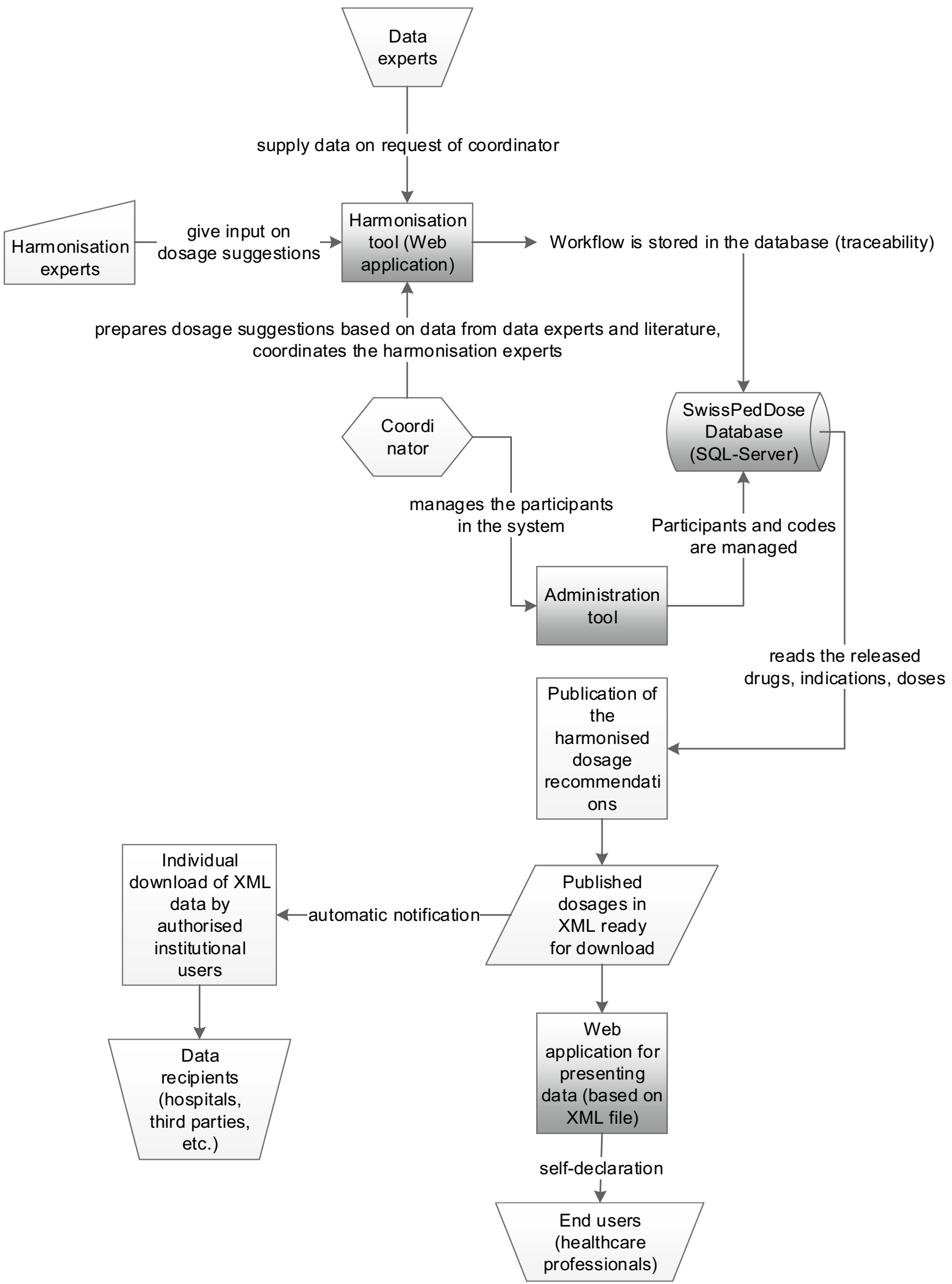


4Fig. 1 Developed tools. The harmonisation process is performed in the web-based harmonisation tool. The complete workflow with every access to and entry of data is stored in an SQL database. Role and personnel information of participants (data and harmonisation experts, coordinators) and used codes (e.g. indications, substances, routes of administration) can be managed in the separated administration tool. The dosage recommendations authorised for publication are exported as XML file. The XML data can be imported in the SwissPedDose web application or downloaded and used from registered data recipients

\section{Process of harmonisation}

Subsequently, the coordinator made a dosage suggestion to be discussed within the respective expert group (Fig. 2). This dosage suggestion results from the highest evidence (e.g. randomised controlled trial or guideline of a medical society) and comparison of practical aspects (e.g. administration modalities and dosage frequencies in order to achieve the best possible compliance) of all dosage recommendations gathered.

The dosage suggestion is entered into the harmonisation tool, the literature summary is attached, validated by a second coordinator and sent to the 8 harmonisation experts. If they agree, they accept it. If they disagree, they can directly mutate the suggestion and have to justify their changes referencing the related evidence and/or scientific literature. All experts are able to view the changes requested along with the respective comments of their colleagues, like in an interactive chatroom. If necessary, the coordinator adapts the dosage suggestion based on the feedback and its scientific evidence. The process is closed when all 8 harmonisation experts in the group agree with the suggestion and a consensus is reached. The consensus and its entry in the harmonisation tool is double checked by a second coordinator and then published as the national harmonised dosage recommendation on the SwissPedDose web application.

\section{Results}

\section{Drug consumption data and collection of in-house dosage recommendations}

The collected drug consumption data, resulted in a "Top 40 list" of the most frequently used drugs in Swiss children's hospitals (Table 1).

The collection of in-house dosage recommendations for these drugs from the participating hospitals revealed that the majority of the children's hospitals in Switzerland have their own dosage databases or booklets, which are historically grown and are often lacking information on their origin. Accordingly, there is heterogeneity with sometimes considerable differences in dosage recommendations. In order to exemplify this fact, Table 2 is providing a summary of in-house data gathered for the antibiotic gentamicin. Information provided was limited to general dosing what usually relates to severe infections and to the age group from $\geq 1$ month to $<12$ years of age. Importantly, gentamicin is an antibiotic known for its potential side effects where therapeutic drug monitoring is required due to the clear link between drug concentrations in the blood and occurrence of nephro- or ototoxicity [45]. The list reveals that there is the need for a harmonisation.

\section{Literature review}

The search for paediatric dosage information in internationally known and well-established drug handbooks and online databases also reveals that these evidence-based/referenced sources contain differing dosage recommendations for the same indication. One illustrative example is shown in Table 3, where we again summarise the dosage recommendations for gentamicin but this time published in the literature references listed.

In this example of intravenous gentamicin, the dosage suggestion made by the coordinator after compiling the internal dosage recommendations of the 8 children's hospitals, performing the literature review and comparing the results was $7.5 \mathrm{mg} / \mathrm{kg} /$ dose q $24 \mathrm{~h}$ with a maximum daily dose of $500 \mathrm{mg} / \mathrm{dose}$ and a trough level of $<2 \mathrm{mg} / \mathrm{L}$. After sending the dosage suggestions to the 8 harmonisation experts specialised in the field of paediatric infectious diseases, they disagreed on the indication of maximum daily dose because evidence was scarce and the availability of dosage adjustment by therapeutic drug monitoring. With agreement of all experts after the second round of harmonisation, the coordinator published the dosage recommendation without a maximum daily dose.

\section{Dosage recommendations}

During the pilot project, a total of 177 data requests for 36 different drugs were sent to the data experts. One hundred forty-eight (83.6\%) of the requests were answered by all 8 data experts. For 105 of the answered tasks, where at least 4 of 8 hospitals provided an internal dosage recommendation, a literature review was performed by the coordinator, and a dosage suggestion was prepared for the harmonisation experts. Of these, 27 (26\%) cases were harmonised in the first round. For 71 (68\%) cases, 2-3 harmonisation rounds were required to reach consensus. In 4 (4\%) cases, more harmonisation rounds were needed. Only in 3 (3\%) cases consensus was not reached. These 3 cases involved the following drugs: ceftazidime (cystic fibrosis, intravenous continuous infusion), ceftriaxone (Lyme disease, intravenous/intramuscular injection), and amoxicillin 


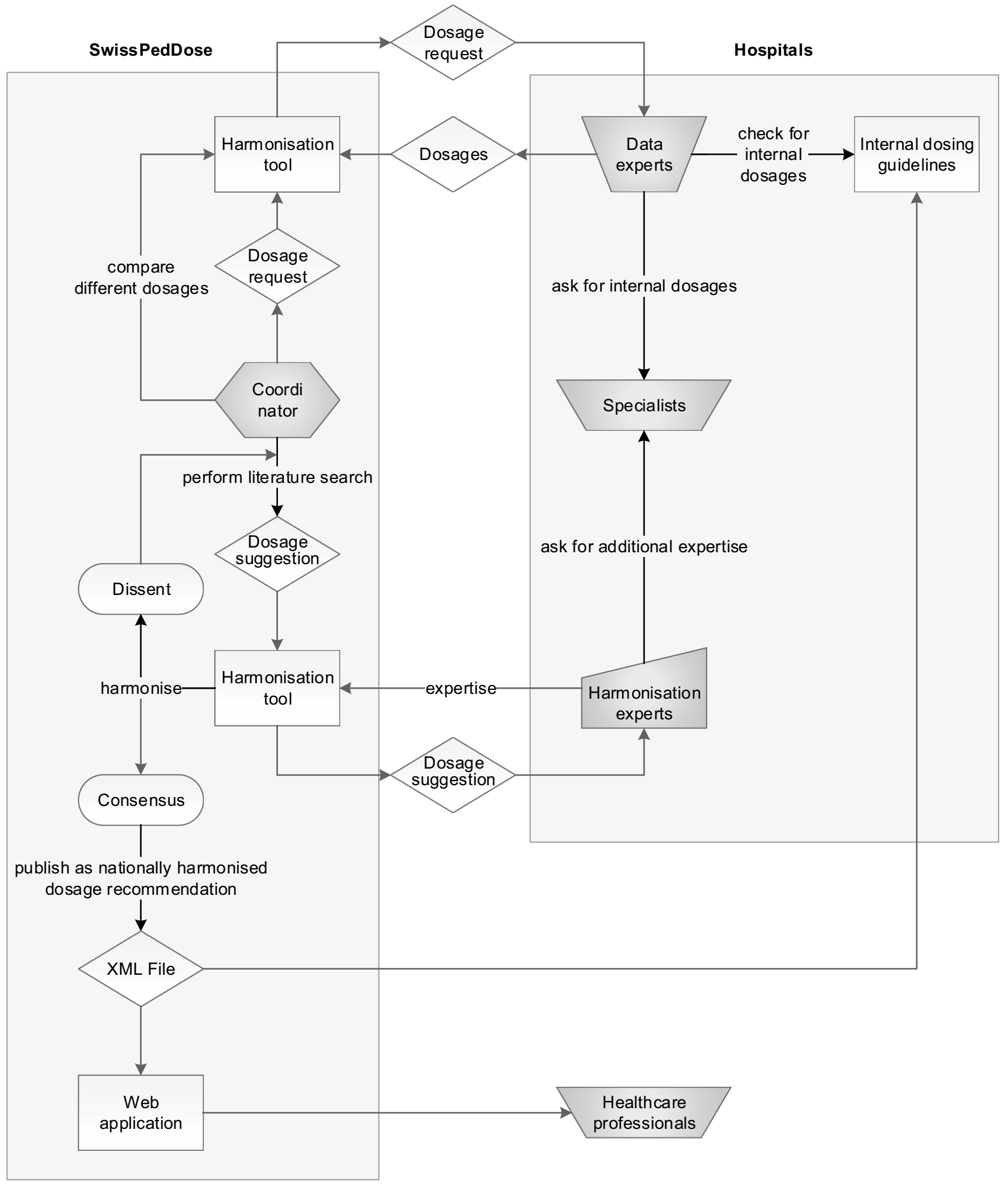

Fig. 2 Schematic depicting the standardised harmonisation process. This process includes the gathering of data, their evaluation and consensus finding. Each step is tracked and digitalised in the harmonisation tool 
Table 1 Summarised top 40 drug list, alphabetically sorted. Shown is the summary of drug consumption data gathered and submitted by the pharmacies of 8 children's hospitals in Switzerland, limited to
40 drugs after processing. For each listed substance, the number of reporting hospitals is stated. "harmonised during pilot project; ${ }^{\star}$ not licensed for children in Switzerland

\begin{tabular}{|c|c|c|c|}
\hline Substance & ATC code & Drug groups [55] & $\begin{array}{l}\text { Number of } \\
\text { reporting } \\
\text { hospitals }\end{array}$ \\
\hline Acyclovir $^{\dagger}$ & J05AB01 & ANTIVIRALS & $4 / 8$ \\
\hline Amoxicllin $^{\dagger}$ & J01CA04 & ANTIBACTERIALS & $8 / 8$ \\
\hline Amoxicillin-clavulanate $^{\dagger}$ & J01CR02 & ANTIBACTERIALS & $7 / 8$ \\
\hline Betamethasone $^{\dagger}$ & H02AB01 & CORTICOSTEROIDS & $4 / 8$ \\
\hline Ceftazidime $^{\dagger}$ & J01DD02 & ANTIBACTERIALS & $5 / 8$ \\
\hline Ceftriaxone $^{\dagger}$ & J01DD04 & ANTIBACTERIALS & $5 / 8$ \\
\hline Cefuroxime $^{\dagger}$ & J01DC02 & ANTIBACTERIALS & $4 / 8$ \\
\hline Clonidine & $\mathrm{C} 02 \mathrm{AC} 01$ & ANTIHYPERTENSIVES & $3 / 8$ \\
\hline Caffeine citrate & N/A & N/A & $5 / 8$ \\
\hline Dexamethasone $^{\dagger}$ & $\mathrm{H} 02 \mathrm{AB} 02$ & CORTICOSTEROIDS & $6 / 8$ \\
\hline Diclofenac $^{\dagger}$ & M01AB05 & $\begin{array}{l}\text { ANTI-INFLAMMATORY AND ANTI-RHEUMATIC PROD- } \\
\text { UCTS }\end{array}$ & $4 / 8$ \\
\hline Epinephrine $^{\dagger}$ & C01CA24 & CARDIAC THERAPY & $5 / 8$ \\
\hline Esomeprazole & $\mathrm{A} 02 \mathrm{BC} 05$ & DRUGS FOR ACID-RELATED DISORDERS & $3 / 8$ \\
\hline Fentanyl $^{\dagger}$ & N01AH01 & ANESTHETICS & $6 / 8$ \\
\hline Fluconazole $^{\dagger}$ & J02AC01 & ANTIMYCOTICS & $3 / 8$ \\
\hline Furosemide $^{\dagger}$ & C03CA01 & DIURETICS & $6 / 8$ \\
\hline Gentamicin $^{\dagger \neq}$ & J01GB03 & ANTIBACTERIALS & $3 / 8$ \\
\hline Heparin $^{\dagger}$ & B01AB01 & ANTITHROMBOTIC AGENTS & $7 / 8$ \\
\hline Hydrochlorothiazide & C03AA03 & DIURETICS & $4 / 8$ \\
\hline Hydrocortisone & Н02АВ09 & CORTICOSTEROIDS & $3 / 8$ \\
\hline Ibuprofen $^{\dagger}$ & M01AE01 & $\begin{array}{l}\text { ANTI-INFLAMMATORY AND ANTIRHEUMATIC PROD- } \\
\text { UCTS }\end{array}$ & $8 / 8$ \\
\hline Infliximab $^{\dagger}$ & L04AB02 & IMMUNOSUPPRESSANTS & $5 / 8$ \\
\hline Macrogol & A06AD15 & DRUGS FOR CONSTIPATION & $4 / 8$ \\
\hline Meclozine & R06AE05 & ANTIHISTAMINES & $3 / 8$ \\
\hline Mefenamic acid & M01AG01 & $\begin{array}{l}\text { ANTI-INFLAMMATORY AND ANTIRHEUMATIC PROD- } \\
\text { UCTS }\end{array}$ & $4 / 8$ \\
\hline Meropenem $^{\dagger}$ & J01DH02 & ANTIBACTERIALS & $3 / 8$ \\
\hline Metamizole & N02BB02 & ANALGESICS & $4 / 8$ \\
\hline Methylprednisolone & H02AB04 & CORTICOSTEROIDS & $3 / 8$ \\
\hline Metronidazole $^{\dagger}$ & P01AB01 and J01XD01 & ANTIPROTOZOALS and ANTIBACTERIALS & $5 / 8$ \\
\hline Midazolam $^{\dagger}$ & N05CD08 & PSYCHOLEPTICS & $7 / 8$ \\
\hline Morphine $^{\dagger}$ & N02AA01 & ANALGESICS & $7 / 8$ \\
\hline Omeprazole & A02BC01 & DRUGS FOR ACID-RELATED DISORDERS & $4 / 8$ \\
\hline Ondansetron $^{\dagger}$ & A04AA01 & ANTI-EMETICS and ANTINAUSEANTS & $7 / 8$ \\
\hline Paracetamol $^{\dagger}$ & N02BE01 & ANALGESICS & $8 / 8$ \\
\hline Prednisolone & H02АB06 & CORTICOSTEROIDS & $4 / 8$ \\
\hline Propofol & N01AX10 & ANESTHETICS & $3 / 8$ \\
\hline Propranolol & C07AA05 & BETA BLOCKING AGENTS & $3 / 8$ \\
\hline Spironolactone $^{\dagger}$ & C03DA01 & DIURETICS & $6 / 8$ \\
\hline Trimethoprim-sulfamethoxazole ${ }^{\dagger}$ & J01EE01 & ANTIBACTERIALS & $3 / 8$ \\
\hline Vancomycin ${ }^{\dagger}$ & A07AA09 and J01XA01 & $\begin{array}{l}\text { ANTIDIARRHEALS, INTESTINAL ANTI-INFLAMMATORY/ } \\
\text { ANTI-INFECTIVE AGENTS and ANTIBACTERIALS }\end{array}$ & $3 / 8$ \\
\hline
\end{tabular}


Table 2 Summary of the in-house dosage recommendations of intravenous gentamicin, extracted from the national database SwissPedDose; ${ }^{\dagger}$ indicates where a 24-h dosing interval applies; ¥indicates where an 8-h dosing interval applies. $n . r$. no in-house recommendation reported

\begin{tabular}{llll}
\hline Hospital & Dosage $(\mathrm{mg} / \mathrm{kg} / \mathrm{dose})$ & Trough level $(\mathrm{mg} / \mathrm{L})$ & $\begin{array}{l}\text { Peak } \\
\text { level } \\
(\mathrm{mg} / \mathrm{L})\end{array}$ \\
\hline 1 & $3.0-7.5^{\dagger}$ & & n.r \\
2 & No gentamicin use & $0.5-2.0$ & $\mathrm{n} . \mathrm{r}$ \\
3 & $7.5^{\dagger}$ & $\mathrm{n} . \mathrm{r}$ & $5-10$ \\
4 & $5.0-7.0^{\dagger}$ & $0-2.0$ & $\mathrm{n} . \mathrm{r}$ \\
5 & $5.0-7.5^{\dagger}$ & $\leq 1.0$ & $6-8$ \\
& $\left(\right.$ max. daily dose $\left.500 \mathrm{mg} / \mathrm{dose}^{\dagger}\right)$ & $<1.0$ & $\mathrm{n} . \mathrm{r}$ \\
6 & Moderate infection: $1.0^{\ddagger}$ & & $\mathrm{n} . \mathrm{r}$ \\
7 & Severe infection: $2.5^{\ddagger}$ & $<0.6-2.0$ & $\mathrm{n} . \mathrm{r}$ \\
8 & $7.5^{\dagger}$ & $<1.0$ & \\
\hline & $<33 \mathrm{~kg}$ body weight: $7.5^{\dagger}$ & $<2.0$ & \\
\hline
\end{tabular}

and beta-lactamase inhibitor (urinary tract infection, oral application).

By the end of the pilot project, a total of 102 national harmonised dosage recommendations were published. These are concerning 30 different drugs in the fields of paediatric infectious diseases, neonatology and general paediatrics. Twenty-six of these drugs were from the top 40 list and 4 additional drugs (amikacin, potassium canrenoate, nalbuphine and teicoplanin) have been harmonised upon request by the stakeholders.

\section{Publishing process and quality management}

The harmonised dosage recommendations can be exported and downloaded as complete XML dataset by institutional users (e.g. hospitals or other authorised third parties) free of charge. If a new XML file is published, the registered users automatically receive a notification. The access to the web application is limited to healthcare professionals upon a mandatory self-declaration.

The harmonisation work was standardised and described in a quality management manual. The manual defines and explains the harmonisation process as well as the technical process of harmonisation in the harmonisation tool. Standard operating procedures (SOPs) for each of the process steps (e.g. literature review) were issued and applied. In addition to the SOPs, the manual contains personnel documents, which define the tasks, profiles and background of each participating person and describes the cooperation of the individual actors in the harmonisation process.

The dosage recommendations are re-evaluated regularly (i.e. when a request is received or at least every 4 years) to ensure that they remain up to date. For example a review of dosage recommendations for intravenous gentamicin dosing has recently resulted in an adjustment of trough level to $<1 \mathrm{mg} / \mathrm{L}[46]$.

Table 3 Summary of dosage recommendations extracted from different literature sources for intravenous gentamicin; n.r. no trough level reported

\begin{tabular}{|c|c|c|c|}
\hline Literature & Dosage $(\mathrm{mg} / \mathrm{kg} / \mathrm{dose})$ & Dosing interval & Trough level $(\mathrm{mg} / \mathrm{L})$ \\
\hline BNF for Children 2016-17 & 7.0 & $\mathrm{q} 24 \mathrm{~h}$ & n.r \\
\hline Kinderformularium, accessed 24.01.2017 & 7.0 & $\mathrm{q} 24 \mathrm{~h}$ & n.r \\
\hline Nelson's Pediatric Antimicrobial Therapy, 22nd Edition 2016 & $3.0-7.5$ & q8-24h & n.r \\
\hline RedBook®, 30th Edition 2015 & $\begin{array}{l}2.0-2.5 \\
5.0-7.5\end{array}$ & $\begin{array}{l}\text { q8h } \\
\text { q24h }\end{array}$ & n.r \\
\hline Shann, F., Drug Doses, 16th Edition 2014 & $\begin{array}{l}\text { Initial 8.0, then } 6.0(1 \\
\text { w-10 y) } \\
\text { Initial } 7.0 \text {, then } 5.0(>10 \\
\text { y) } \\
\text { Max. daily dose } 240- \\
360 \mathrm{mg} / \text { dose }\end{array}$ & $\mathrm{q} 24 \mathrm{~h}$ & $<1.0$ \\
\hline SmPC Gentamicin-ratiopharm ${ }^{\circledR}$, accessed 24.01.2017 & $\begin{array}{l}4.5-7.5(1 \mathrm{~m}-3 \mathrm{y}) \\
3.0-6.0(3-17 \mathrm{y})\end{array}$ & q12-24h & $\begin{array}{l}<1.0(\mathrm{q} 24 \mathrm{~h}) \\
<2.0(\mathrm{q} 12 \mathrm{~h})\end{array}$ \\
\hline UpToDate $®$, accessed 24.01.2017 & $\begin{array}{l}2.0-2.5 \\
4.5-7.5\end{array}$ & $\begin{array}{l}\text { q8h } \\
\text { q24h }\end{array}$ & n.r \\
\hline
\end{tabular}




\section{Discussion}

Here, we describe the pilot project of the SwissPedDose database, in which we applied a standardised process for the national harmonisation of dosage recommendations for paediatric patients. The overarching goal behind this initiative is to improve quality of dosage recommendations and pharmacotherapy of children by making recommendations widely available that are based on the latest scientific evidence and approved by respective clinical experts. This we see as most relevant as dosages by drug label in practice are not yet available or frequently enough not optimally adapted to children [47].

The development of an IT tool to guide and track all process steps and a web application to provide the recommendations to all healthcare professionals are the good result and substantial merit of this project. The tools allow traceability in line with quality assessment needs. Importantly, the interprofessional approach involved both hospital pharmacists and senior paediatricians of the largest children's hospitals in Switzerland, thereby strengthening acceptance and support of the project objectives which is of utmost relevance for implementation. In all of the participating hospitals, the harmonisation process led to an update of previously used in-house dosage recommendation by implementation, indeed illustrating a quality improvement step. However, the involvement of 8 hospitals and the very high degree of traceability inevitably led to a slow and complex process that has resulted in a comparatively small number of harmonised dosage recommendations at this first stage.

We expect that implementation and extension of the harmonised and regularly re-evaluated dosage recommendations simplify the dosage-finding and prescription of medicinal products in children and will contribute to an increased efficacy and safety in paediatric drug therapy. This will have to be tested in future studies. To ensure implementation after the pilot phase, all participating children's hospitals have signed a letter of intent to integrate the SwissPedDose dosage recommendations into their clinical information systems. In the meantime, all these children's hospitals have implemented this goal.

A limitation of SwissPedDose is that for practical reasons the published dosage recommendations are in $\mathrm{mg} / \mathrm{kg}$ body weight or $\mathrm{mg} / \mathrm{m}^{2}$ body surface what partly leaves agedependant pharmacokinetic variability unconsidered [48]. The individual dosage must be calculated what bears the risks of dosing errors [23]. In some cases, where appropriate dosing information for special drugs, indications and age categories is lacking, further data is needed to optimise dosage recommendations.

It is important to identify and communicate these needs as research questions to the research community, to eventually induce appropriate clinical trials or physiologically based pharmacokinetic modelling. We were following this approach for the antibiotic gentamicin $[49,50]$.

With the established harmonisation process, it was possible to achieve national standardisation for 102 off-label dosage recommendations of 30 various drugs for children. Paediatric drug dose information sources from other countries such as Kinderformularium (NL), Lexicomp® (USA) and BNF for Children (UK) are comparable and follow a similar approach [35, 51, 52]. The Dutch group managing the Kinderformularium recently established the BRAvO framework, which offers a structured assessment of benefits and risks of off-label drug use in children [53]. We expect that the proposed benefit/risk assessment will further promote safe pharmacotherapy, when applied to the SwissPedDose dosage recommendations.

The development of a dedicated electronic tool to guide and trace the harmonisation process is unique for Switzerland. The tool could be useful for international harmonisation and the establishment of a European formulary. This is worth consideration, because there is no international consensus on which dose to adopt. Consensus may be difficult to achieve, as compilation varies by the review of available scientific evidence, and drug use is based on national clinical experience, when studies are lacking [54].

The project described herein was successful, and the milestones set at the beginning of the project were reached, so that it was possible to start a regular operation of the database from April 2018. At the time of writing, 448 dosage recommendations on 134 drugs are accessible at https:// swisspeddose.ch/database.

Acknowledgements The authors would like to thank all members of the managing board and experts who voluntary contributed to the pilot project (U. Frey, U. Heininger, S. Wellmann, R. Glanzmann and V. Gotta from University Children's Hospital Basel. Ch. Aebi, A. Duppenthaler, M. Nelle-Genauer, J. McDougall and R. Halder from INSELSPITAL Bern. K. Posfay-Barbe, R. Pfister and C. Fonzo-Christe from Hôpitaux Universitaires de Genève. Ch. Kind, T. Guidi, Ch. Kahlert, J. Micallef, S. Böhm and B. Wohlwend from OKS, St. Gallen, T. Neuhaus, M. Fontana, M. Büttcher and J. Rogger from Cantonal Hospital of Lucerne. S. Asner, P.-A. Crisinel, J.-B. Armengaud, E. Giannoni and E. Di Paolo from Centre hospitalier universitaire vaudois. H. Köhler, S. BernhardStirnemann, P. Meyer and C. Zaugg from Cantonal Hospital of Aarau. F. Kunz, Ch. Nather and M. Cont from University Children's Hospital Zurich. R. Arlettaz Mieth from University Hospital Zurich. E. Martinelli from Swiss Association of Public Health Administration and Hospital Pharmacists (GSASA)). M. Cichocki from Infoserv, Evilard for software development. O. Dolder, M. Duarte and St. Riederer from Interface Politikstudien Forschung Beratung $\mathrm{GmbH}$, Lucerne for consultation and pilot project controlling, A. Bombelli and M. Skouhus from Skouhus \& Bombelli AG, Lucerne for corporate identity and web design. S. N. de Wildt (NL), A. Neubert (DE), C. Fonzo-Christe (CH) and D. Tuthill (GB) for participation in an international peer review of the pilot project in 2017. P. Vonbach from Pedeus AG for consultation and permission for the adoption of the initial database structure from the paediatric formulary of the University Children's Hospital Zurich that she built up. J. N. van der Anker, M. Pfister, A. Fuchs, F. Rodieux from 
SwissPedPha, University Children's Hospital Basel and T. Berger for the collaboration - collection of dosage recommendations in Swiss neonatal intensive care units and preparation of dosage suggestions for the field of neonatology.

Authors' contributions RT coordinated the pilot project and was part of the operational project management. She drafted the initial manuscript and approved the final manuscript as submitted. DP worked as a coordinating pharmacist in the pilot project and reviewed and revised the manuscript. SA is an IT specialist and owner of Infoserv. He developed the software for the harmonisation and the admin tool and reviewed the manuscript. ST is a scientific advisor of the Federal Office of Public Health and was responsible for the pilot project. She reviewed the manuscript. HMzS is a professor for biopharmacy and supervises the thesis of RT in paediatric pharmacology. She designed, reviewed and revised the manuscript. CB initiated the development of the Swiss database. He was the pilot project leader and a founder of the SwissPedDose association. He reviewed and revised the manuscript.

Funding Open access funding provided by University of Zurich. Federal Office of Public health (2013-2018) and the Conference of Cantonal Health Directors funded the pilot project. The overall budget for 5 years (2013-2018) was EUR 720,000, including EUR 285,000 for IT. The contract for the operation and further development of the paediatric database was put out to public tender by the Federal Government in 2017. The purpose of the tender was to select a competent and reliable provider who will be able to provide the medical services required for the ongoing implementation of paediatric drug harmonisation during the operating phase from April 2018. The stakeholders (Directors of the Swiss Children's Hospitals (Collège A), GSASA, and Swiss Society of Paediatrics) and the project management of the pilot project then founded the SwissPedDose association and submitted an offer to the government for the operation of the database and continuation of the harmonisation work. In September 2017, SwissPedDose was awarded successfully. An annual sum of EUR 500,000 will be made available for this purpose.

Availability of data and material The data that support the findings of this project are available from the corresponding author upon request.

Code availability Not applicable.

\section{Declarations}

Ethics approval Not required.

Consent to participate Not required.

Consent for publication All the authors consented for publication.

Competing interests The authors declare no competing interests. Only ST who is employed by the FOPH has a financial relationship with the organizations that sponsored the pilot project to declare.

Disclaimer The revised Therapeutic Products Act and the implementing provisions define the responsibilities of the SwissPedDose association and the FOPH respectively in the implementation of the national database.

Open Access This article is licensed under a Creative Commons Attribution 4.0 International License, which permits use, sharing, adaptation, distribution and reproduction in any medium or format, as long as you give appropriate credit to the original author(s) and the source, provide a link to the Creative Commons licence, and indicate if changes were made. The images or other third party material in this article are included in the article's Creative Commons licence, unless indicated otherwise in a credit line to the material. If material is not included in the article's Creative Commons licence and your intended use is not permitted by statutory regulation or exceeds the permitted use, you will need to obtain permission directly from the copyright holder. To view a copy of this licence, visit http://creativecommons.org/licenses/by/4.0/.

\section{References}

1. Shirkey H (1968) Therapeutic orphans. J Pediatr 72(1):119-120

2. Government U.S. Best Pharmaceuticals for Children Act (2002) available at https://www.congress.gov/107/plaws/publ109/PLAW-107pub1109. pdf (last accessed 06 November 2019)

3. Government U.S. Pediatric Research Equity Act of 2003 (2003) available at https://www.congress.gov/108/plaws/publ155/PLAW-108publ155. pdf (last accessed 06 November 2019)

4. Union E.P.a.C.o.t.E., Regulation (EC) No 1901/2006 on medicinal products for paediatric use (2006) available at https://ec.europa. eu/health//sites/health/files/files/eudralex/vol-1/reg_2006_1901/ reg_2006_1901_en.pdf (last accessed 30 October 2019)

5. Burckart GJ, Kim C (2020) The revolution in pediatric drug development and drug use: therapeutic orphans no more. J Pediatr Pharmacol Ther 25(7):565-573

6. Wimmer S, Rascher W, Neubert A (2019) How often do SmPCs contain contraindications and special warnings that are specific for the paediatric population. Klin Padiatr 231(4):191-198

7. Commission E Off-label use of medicinal products (2017) available at https://ec.europa.eu/health/sites/health/files/files/committee/stamp/ stamp6_off_label_use_background.pdf (last accessed 06 November 2019)

8. Di Paolo ER et al (2006) Unlicensed and off-label drug use in a Swiss paediatric university hospital. Swiss Med Wkly 136(13-14):218-222

9. Shah SS et al (2007) Off-label drug use in hospitalized children. Arch Pediatr Adolesc Med 161(3):282-290

10. Pandolfini C, Bonati M (2005) A literature review on off-label drug use in children. Eur J Pediatr 164(9):552-558

11. Lindell-Osuagwu L et al (2009) Off-label and unlicensed drug prescribing in three paediatric wards in Finland and review of the international literature. J Clin Pharm Ther 34(3):277-287

12. Lindell-Osuagwu L et al (2014) Prescribing for off-label use and unauthorized medicines in three paediatric wards in Finland, the status before and after the European Union Paediatric Regulation. J Clin Pharm Ther 39(2):144-153

13. Yackey K et al (2019) Off-label medication prescribing patterns in pediatrics: an update. Hosp Pediatr 9(3):186-193

14. Committee on Drugs A Uses of drugs not described in the package insert (off-label uses) (2002) Pediatrics 110(1 Pt 1):181-3

15. Conroy S et al (2000) Survey of unlicensed and off label drug use in paediatric wards in European countries. European Network for Drug Investigation in Children. BMJ 320(7227):79-82

16. Schrier L et al (2020) Off-label use of medicines in neonates, infants, children, and adolescents: a joint policy statement by the European Academy of Paediatrics and the European society for Developmental Perinatal and Pediatric Pharmacology. Eur J Pediatr 179(5):839-847

17. Kaley VR et al (2019) Trends in the off-label use of beta-blockers in pediatric patients. Pediatr Int 61(11):1071-1080

18. Ziesenitz VC et al (2017) Efficacy and safety of ibuprofen in infants aged between 3 and 6 months. Paediatr Drugs 19(4):277-290

19. Rose K, Walson PD (2017) Do paediatric investigation plans (PIPs) advance paediatric healthcare? Paediatr Drugs 19(6):515-522

20. De Bruyne $\mathrm{P}$ et al (2017) Are antihistamines effective in children? A review of the evidence. Arch Dis Child 102(1):56-60 
21. Busch G (2008) Kinder und Arzneimittel: unbefriedigende Situation heute - was nun? Federal Office of Public Health: available at https://www.bag.admin.ch/dam/bag/de/dokumente/biomed/ heilmittel/kinder-arzneimittel-unbefriedigende-situation.pdf. download.pdf/kinderarzneimittel-de.pdf (last accessed 20 October 2019)

22. Kaushal $\mathrm{R}$ et al (2001) Medication errors and adverse drug events in pediatric inpatients. JAMA 285(16):2114-2120

23. Alghamdi AA et al (2019) Prevalence and nature of medication errors and preventable adverse drug events in paediatric and neonatal intensive care settings: a systematic review. Drug Saf 42(12):1423-1436

24. Gonzales K (2010) Medication administration errors and the pediatric population: a systematic search of the literature. J Pediatr Nurs 25(6):555-565

25. Neville KA et al (2014) Off-label use of drugs in children. Pediatrics 133(3):563-567

26. van der Zanden TM et al (2017) Developing a paediatric drug formulary for the Netherlands. Arch Dis Child 102(4):357-361

27. Confederation T.F.A.o.t.S., Therapeutic Products Act (2000) (Status as of 1 January 2019): available at https://www.admin.ch/opc/en/classifiedcompilation/20002716/index.html (last accessed 25 October 2019).

28. Arzneimittel Information Publikations System AIPS. Available from: https://www.swissmedicinfo.ch/.

29. European Medicines Agency (EMA). Available from: https:// www.ema.europa.eu.

30. U.S. Food and Drug Administration (FDA). Available from: https://www.accessdata.fda.gov/scripts/cder/daf/.

31. UpToDate. Available from: https://www.uptodate.com.

32. Taketomo C (2017) Pediatric \& Neonatal Dosage Handbook. 23rd ed. Wolters Kluwer

33. Committee P.F. BNF for children 2016-2017 (2016) BMJ Group and Pharmaceutical Press

34. Shann F (2014) Drug doses. 16th ed. Collective Pty, Limited

35. NKFK. Kinderformularium. Available from: https://kinderformularium. $\mathrm{nl}$.

36. Yaffe SJ, Aranda JV (2015) Neonatal and pediatric pharmacology: therapeutic principles in practice. Wolters Kluwer

37. Hughes HK, Kahl LK (2017) The Harriet Lane Handbook. 21st ed. Elsevier

38. Kimberlin DW et al (2015) Red Book: 2015 Report of the Committee on Infectious Diseases. 30th ed. American Academy of Pediatrics
39. Bradley JS et al (2016) Nelson's pediatric antimicrobial therapy. 22nd ed. American Academy of Pediatrics.

40. Pédiadol. Available from: https://pediadol.org/.

41. Micromedex. Available from: https://www.micromedexsolutions. com.

42. Berner R, Bialek R, Borte M (2013) DGPI Handbuch: Infektionen bei Kindern und Jugendlichen. 6. ed. Georg Thieme Verlag

43. PIGS. Recommendations and guidelines. Available from: http:// www.pigs.ch/pigs/frames/documentsframe.html.

44. Neofax. Available from: https://www.micromedexsolutions.com.

45. Touw DJ, Westerman EM, Sprij AJ (2009) Therapeutic drug monitoring of aminoglycosides in neonates. Clin Pharmacokinet 48(2):71-88

46. SwissPedDose. Available from: https://swisspeddose.ch/database.

47. Tomasi PA et al (2017) Enabling development of paediatric medicines in Europe: 10 years of the EU Paediatric Regulation. Paediatr Drugs 19(6):505-513

48. Gotta V et al (2021) Prinzipien der medikamentösen Dosierung bei Kindern. Swiss Med Forum (21(2728)):466-4712

49. Paioni $\mathrm{P}$ et al (2021) Gentamicin population pharmacokinetics in pediatric patients - a prospective study with data analysis using the saemix package in R. 13(10):1596

50. Goers R et al (2021) SwissPK ${ }^{\mathrm{cdw}}$ - A clinical data warehouse for the optimization of pediatric dosing regimens. CPT Pharmacometrics Syst Pharmacol 00: 1- 10

51. Lexicomp. Available from: https://online.lexi.com.

52. Committee P.F. BNF for children 2020-2021 (2020) BMJ Group and Pharmaceutical Press

53. van der Zanden TM et al (2021) Benefit-risk assessment of offlabel drug use in children: the Bravo framework. Clin Pharmacol Ther 110(4):952-965

54. Haslund-Krog SS et al (2018) Development of one paediatric and one neonatal formulary list in hospital settings. Br J Clin Pharmacol 84(2):349-357

55. WHOCC - ATC/DDD Index. Available from: https://www.whocc. no/atc_ddd_index/ (last accessed 22 April 2021)

Publisher's Note Springer Nature remains neutral with regard to jurisdictional claims in published maps and institutional affiliations. 